\title{
A Multicriteria Decision Model for Supplier Selection in a Food Industry Based on FITradeoff Method
}

\author{
Eduarda Asfora Frej, Lucia Reis Peixoto Roselli, \\ Jônatas Araújo de Almeida, and Adiel Teixeira de Almeida
}

Center for Decision Systems and Information Development (CDSID), Universidade Federal de Pernambuco, Av. Acadêmico Hélio Ramos, s/n, Cidade Universitária, 50740-530 Recife, PE, Brazil

Correspondence should be addressed to Eduarda Asfora Frej; eafrej@cdsid.org.br

Received 16 May 2017; Revised 9 August 2017; Accepted 6 September 2017; Published 19 October 2017

Academic Editor: Josefa Mula

Copyright (C) 2017 Eduarda Asfora Frej et al. This is an open access article distributed under the Creative Commons Attribution License, which permits unrestricted use, distribution, and reproduction in any medium, provided the original work is properly cited.

\begin{abstract}
This article puts forward a decision model for solving a supplier selection problem in a food industry by considering multiple objectives that influence the decision-making process. In times of increasing competitiveness, companies strive hard to improve their profitability, and selection of supply sources may help if an appropriate decision is made through a well-structured decisionmaking process. Preference modeling is conducted in a flexible and interactive elicitation manner with the decision-maker (DM), aided by FITradeoff method. Partial information is gathered about the DM's preferences in such a way that less effort is spent on finding a final solution for the problem.
\end{abstract}

\section{Introduction}

One of the main decision-making problems faced by organizations is the supplier selection problem. How to select supply sources is a strategic decision for companies, since doing so successfully enables them to reduce their costs and improve profits [1]. Choosing a source of supply is one of the most critical activities of supply chain management, because a wrong choice can lead the supply chain as a whole to suffer losses and thus this would directly affect the performance of the organizations involved. On the other hand, appropriate decisions can reduce purchasing costs, decrease production lead time, increase customer satisfaction, and strengthen the competitiveness of organizations [2].

Companies frequently misunderstand the supplier selection problem as a single-criterion decision-making problem, taking into account only cost factors when making decisions. This approach is inefficient, since there are other quantitative and qualitative factors that should be considered. Tradeoffs between multiple and conflicting objectives have to be made in order to select the best supplier [3].

Several supplier selection problems are addressed in the literature as multiple criteria decision-making problems.
Ho et al. [4] review the main MCDM approaches for supplier selection problems between 2000 and 2008. Chai et al. [5] provide a guide to studies on supplier selection with MCDM from 2009 to 2012 based on four aspects: decision problems, decision-makers, decision environments, and decision approaches.

In this context, this article sets out to build a multicriteria decision model to solve a supplier selection problem in a food company by considering a purchasing manager's preferences in order to select a source of supply for packaging material of a new product that the company is going to start manufacturing. Preference modeling is conducted through a compensatory approach, aided by the Flexible and Interactive Tradeoff method, FITradeoff [6].

The FITradeoff method was developed to elicit criteria weights within the scope of Multiattribute Value Theory [7] in a structured way, based on tradeoffs. The main feature of this new methodology compared to the traditional tradeoff elicitation procedure is that FITradeoff works with partial information about the DM's preferences and thus it requires less cognitive effort from the DM during the elicitation process [6]. Partial information approaches for MCDM were mainly developed by the fact that the information required by 
traditional methods can be tedious and time-consuming [8], and the DM may not be willing to give information in the detailed way required [9]. There are several ways of dealing with partial information provided by the DM in the elicitation process. Dominance intensity methods consider the information given by DMs to run linear programming problems so as to build a pairwise dominance matrix and thus rank the alternatives based on incomplete information regarding criteria weights [10-12]. The FITradeoff method works based on the concept of potential optimality in order to choose the best alternative in a determined set of possible actions, based on tradeoff judgments given by DMs. FITradeoff improves the applicability of the traditional tradeoff procedure [6], providing an easier decision-making process. The elicitation is conducted interactively with the DM through a Decision Support System, which provides graphical visualization to help the DM in the analyses of partial results. More details about this MCDM method are provided in Section 3.

This paper is organized as follows: Section 2 presents a brief literature review about MCDM approaches for supplier selection problems; Section 3 explains how the FITradeoff method works for aiding MCDM problems; Section 4 sets out the multiple criteria model for supplier selection and describes the application in a food industry; and finally some conclusions regarding this application are discussed in Section 5 .

\section{Literature Related to Supplier Selection Problems}

Most organizations that produce goods or services, at some point in the process, need some components that they do not produce internally. When such situations happen, a purchasing process must be started. According to Slack et al. [13], despite the variety of purchasing activities inside organizations, five performance objectives should always be taken into account, quality, speed, credibility, flexibility, and price, in order to ensure that suppliers' systems and performance are in accordance with the objectives of the organization.

The high dependency between organizations regarding the purchasing process makes supplier selection a strategic process for organizations. Organizations seek long-term relationships with their suppliers, based on trust and commitment, so that favorable results can be achieved jointly. Despite the strategic importance of the supplier selection process, many organizations still limit themselves to evaluating the price performance goal as the sole determiner when choosing a supplier. The evaluation of this single criterion, however, is not the most adequate approach, since many other factors must be taken into account for the selection process to be effective [1]. Weber and Current [14] list at least twenty-three criteria that can be considered when it comes to supplier selection problems.

Therefore, it can be observed that supplier selection problems have two main characteristics: they are strategically important and complex. These situations are characterized as problems where at least two alternatives of action are driven by the desire to meet multiple objectives that often conflict with each other, categorized as multicriteria decision problems [15].

In this context, several supplier selection problems in the literature are tackled within a multiple criteria approach, and different MCDM methods are applied to evaluate the alternatives, according to the DM's preference structure, in the context of the problem [15]. Some of these MCDM approaches to supplier selection problems are discussed below.

Regarding the decision actors of the process, either a unique DM or a group of them may be involved in supplier selection problems. As to selecting a single supplier, Dweiri et al. [16] propose a decision support model to solve a supplier selection problem in the automotive industry in Pakistan based on the Analytic Hierarchy Process (AHP). Within a group decision-making context, Li et al. [17] approached a cloud service supplier selection problem based on AHP and TOPSIS methods.

Supplier selection problems can be present in both certainty and uncertainty environments. An uncertainty environment was approached by Çakır [18] who proposes a supplier selection model involved in a decision process with imprecise and subjective information; in this paper, an algorithm based on Fuzzy Analytic Hierarchical Process (FAHP) and Choquet Fuzzy Integral (CFI) methods is developed. In the same way, Dursun and Karsak [19] propose a fuzzy multicriteria group decision approach for supplier selection based on Quality Function Deployment (QFD) and the Fuzzy Weighted Average (FWA) method for dealing with imprecise and subjective information.

A supplier selection situation can be involved in an environment of risk operations. Xiao et al. [20] propose a decision model to solve a supplier selection problem under operational risks based on integrating a Fuzzy Cognitive Map (FCM) and a fuzzy soft set model with the Analytic Network Process (ANP).

As a result of the growing concern about environmental issues, Hamdam and Cheaitou [21] presented a multicriteria decision problem to deal with green supplier selection based on combining two MCDM methods: fuzzy TOPSIS and AHP. In the same way, Kannan et al. [22] approached Green Supply Chain Management (GSCM) in a multicriteria decision problem to select the best green supplier for a plastics manufacturer in Singapore, using Fuzzy Axiomatic Design (FAD). Another green supplier selection problem was approached by Tsui and Wen [23] within a group decision-making context.

A noncompensatory rationality was considered by Gonçalo and Alencar [24] who proposed a multicriteria decision support model for supplier selection which had two phases: the analysis of suppliers' products/services that needed to be evaluated using the PROMSORT method and the analysis of suppliers whose products/services are considered crucial using PROMETHEE II. Awasthi et al. [25] presented a multicriteria decision-making approach using the TOPSIS method with partial information.

Therefore, due to their strategic importance for organizations, supplier selection problems need to be modeled carefully, by considering the particular and individual issues related to each specific situation. In this context, this study aims to model a supplier selection problem of 
packaging material in a food industry within a multiple criteria approach, considering a compensatory rationality for modeling the decision-maker's preferences with FITradeoff method. This new partial information method was also applied by Henriques de Gusmão and Pereira Medeiros [26] for selecting a strategic information system.

\section{FITradeoff Method}

The Flexible and Interactive Tradeoff (FITradeoff) method [6] was developed for eliciting scale constants $\left(k_{i}\right)$ of criteria (for simplicity's sake, in this paper, sometimes the expression criteria weight is used but with meaning of scale constant) within the scope of Multiattribute Value Theory (MAVT), in which alternatives are scored straightforwardly according to the value function in the following equation:

$$
v\left(a_{j}\right)=\sum_{i=1}^{n} k_{i} v_{i}\left(a_{j}\right)
$$

This new method incorporates the axiomatic structure of the traditional tradeoff procedure [7] but improves its applicability for the DM: the information required by FITradeoff is cognitively easier to provide, because this new method works with partial information about the DM's preferences, searching for potentially optimal alternatives inside a space of weights, by solving linear programming problems (LPP) [6].

Considering a multicriteria decision problem with $m$ alternatives and $n$ criteria and a DM with a compensatory rationality, the FITradeoff method follows the steps that are described below.

The first step is for the DM to rank the criteria weights. This step is conducted in the same way as in the traditional tradeoff procedure [7]. Thus, considering $k_{1}$ as the most preferable criteria and $k_{n}$ as the least preferable criteria, the following relationship is obtained after this step:

$$
k_{1}>k_{2}>k_{3}>\cdots>k_{n} \text {. }
$$

After this information has been provided, a preliminary weight space (2) is obtained. Thus, the potential optimality of each alternative will be verified by linear programming problems in order to identify which alternatives are dominated (and thus eliminated from the decision process) and which ones continue in the process as potentially optimal alternatives for the problem. An alternative is potentially optimal if its value in (1) is greater than or equal to the values of all other alternatives for at least one vector of weights inside the weight space [6]; that is, an alternative $a_{j}$ is potentially optimal if the following inequality is satisfied:

$$
\sum_{i=1}^{n} k_{i} v_{i}\left(x_{i j}\right) \geq \sum_{i=1}^{n} k_{i} v_{i}\left(x_{i z}\right) \quad \forall z=1, \ldots, m, z \neq j .
$$

In order to verify the potential optimality of an alternative $a_{j}$ at this point, the value of $a_{j}$ is maximized by an LPP model with the objective function in (4) (where the decision variables are the scale constants $k_{i}$ ) subject to the constraints in (2) and (3) and considering nonnegative and normalized weights.

$$
\max \sum_{i=1}^{n} k_{i} v_{i}\left(x_{i j}\right)
$$

If the LPP model for alternative $a_{j}$ has a feasible solution, then $a_{j}$ is potentially optimal for the problem; otherwise, $a_{j}$ is eliminated from the decision-making process.

After running the LPP model for all $m$ alternatives, if only one alternative is found to be potentially optimal, then a single solution for the problem has been found and the process finishes at this point. Otherwise, the DM proceeds to the next step: he/she starts answering elicitation questions by considering tradeoffs between consequences.

In this next step, the DM compares two fictitious consequences, considering tradeoffs amongst criteria [6]. An interesting point to highlight here is the fact that the comparisons are made based on strict preference statements, unlike what happens in the traditional tradeoff procedure, in which the $\mathrm{DM}$ is required to specify the exact point $x_{i}^{I}$ at which two consequences are indifferent for him [7].

The main feature of FITradeoff compared to the traditional tradeoff procedure is the absence of specifying an indifference point $\left(x_{i}^{I}\right)$. In FITradeoff, points above $\left(x_{i}^{\prime}\right)$ and below $\left(x_{i}^{\prime \prime}\right)$ the indifference value can be found, depending on the answeres given by the DM in the elicitation questions. It is cognitively difficult for the DM to specify indifference relations between consequences, so that a high inconsistency rate is observed when applying the traditional tradeoff procedure [27]. Strict preference statements are easier to provide, and thus a reduction in inconsistencies is expected when applying FITradeoff [6].

Therefore, rather than obtaining equations from indifferent statements, FITradeoff works with partial information in the form of inequalities (5) and (6) obtained from strict preference statements given by the DM.

$$
\begin{gathered}
k_{i} v_{i}\left(x_{i}^{\prime}\right) \geq k_{i+1}, \\
k_{i} v_{i}\left(x_{i}^{\prime \prime}\right) \leq k_{i+1} .
\end{gathered}
$$

These inequalities, jointly with (2), form the new updated space of weights. At this point, the LPP model is run again with (5) and (6) as new constraints, with a view to finding the new set of potentially optimal alternatives for the problem, based on the updated weight space.

In the FITradeoff method, after the DM gives each answer, a new inequality of type (5) and/or (6) is obtained, such that the weight space is updated and the LPP is run again, thereby seeking to find potentially optimal alternatives. This interactive process goes on until a unique solution is found or until the DM is not willing to give additional information [6].

The elicitation of FITradeoff is conducted with the DM by means of a Decision Support System (DSS). The DSS provides the DM with a graphical visualization of the partial results, so that he/she can better analyze and compare the performances of the current potentially optimal alternatives. At this stage, if these partial results are already sufficient 


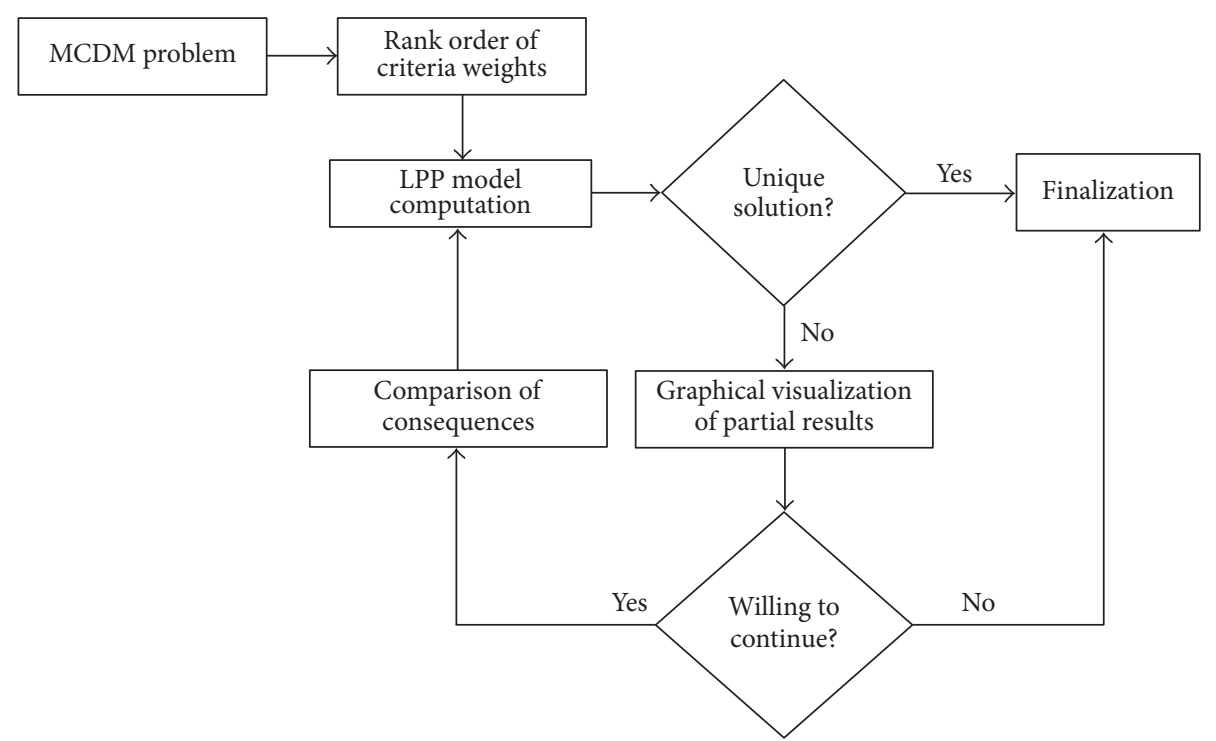

FIgURE 1: FITradeoff method.

for his/her purposes, the DM has the flexibility to stop the process before the elicitation ends and keeps the partial results. Otherwise, the DM continues answering questions until a unique solution is found or until he/she is no longer able to provide more information. The FITradeoff process is summarized in Figure 1.

\section{MCDM Model for the Supplier Selection Problem}

This section sets out to build a multiple criteria decision model based on the FITradeoff method so as to solve a supplier selection problem in a food industry. The organization is a multinational company that owns global brands, and the factory studied is located in Pernambuco, Brazil. The problem that is addressed is how best to select a vendor who will supply packaging material for a new product that this company is about to start manufacturing. Figure 2 summarizes the framework for modeling this decision problem, which was built based on a structured framework [15].

The first step is to characterize the DM and other actors of the decision-making process. In this case, the DM is the manager of the purchasing department of the company who is responsible for decisions of this kind. Other actors are also involved in the decision problem. Analysts from the planning, quality, and logistics department can contribute by providing factual information for this problem, since their routine at work is strongly connected to scheduling (planning), delivering (logistics), and inspection (quality) of raw/packaging materials. Therefore, these other actors can contribute as specialists who will help define criteria and alternatives for this problem.

In the second step of the model, the set of potential suppliers and the criteria to evaluate them are defined. The supplier selection problem addressed here has only five potential suppliers that can be considered as alternatives for this

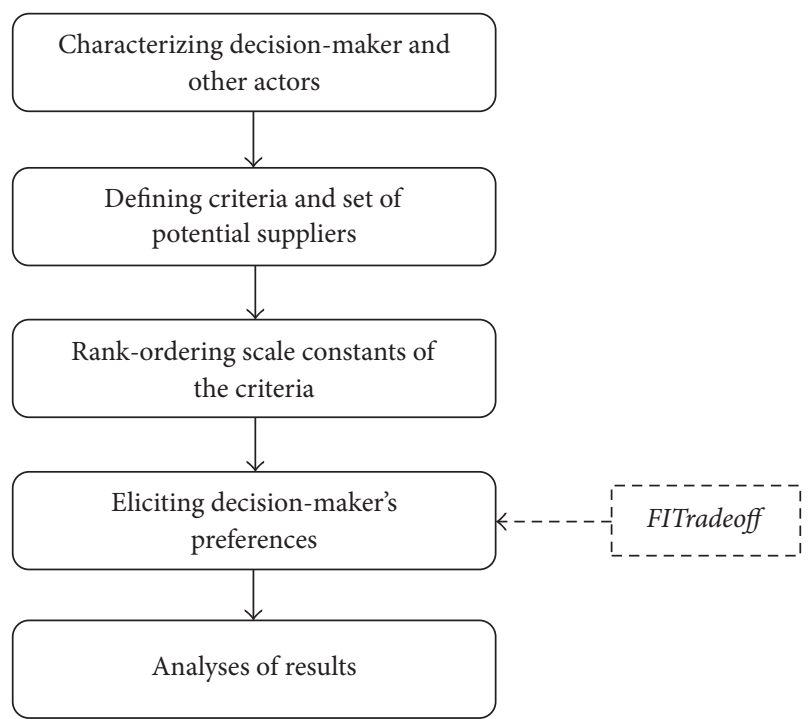

FIGURE 2: Decision model for supplier selection problem based on FITradeoff.

problem. This is because this industry belongs to a multinational company with high quality standards, and thus it preapproves suppliers who are considered able to meet the minimal requirements needed. In this case, only these five vendors have passed this stage, and thus they are then considered as potential candidates to supply the packaging material for a product that the company is about to start manufacturing.

Thus, the set of alternatives is $\mathrm{A}=\{$ Supplier 1; Supplier 2; Supplier 3; Supplier 4; Supplier 5\}. Regarding the set of criteria to evaluate these potential suppliers, the DM, together with other analysts from the company, defined seven criteria, which are listed in Table 1. 
TABLE 1: Description of criteria.

\begin{tabular}{|c|c|c|}
\hline Criteria & Description & Objective \\
\hline Price & Amount paid for one kilogram of the packaging material ( $\mathrm{R} \$ / \mathrm{kg})$. & Minimize \\
\hline Freight & $\begin{array}{l}\text { Related to the reliability of the transport. Subjectively measured on a } 0-1 \text { scale } \\
\text { ( } 1 \text { is the most reliable), based on personal judgments of the decision actors. }\end{array}$ & Maximize \\
\hline Accuracy & $\begin{array}{l}\text { Rate of deliveries with the correct amount ordered, measured in periods of } \\
\text { one month: deliveries with correct amount/total of deliveries. }\end{array}$ & Maximize \\
\hline Promptness & $\begin{array}{l}\text { Rate of deliveries on time, measured in periods of one month: deliveries on } \\
\text { time/total of deliveries. }\end{array}$ & Maximize \\
\hline Quality & $\begin{array}{l}\text { Rate of deliveries with no damage in materials, measured in periods of one } \\
\text { month: deliveries with no damaged material/total of deliveries. }\end{array}$ & Maximize \\
\hline Lead time & $\begin{array}{l}\text { Time computed from the date of receiving the purchase order to the date of } \\
\text { the delivery (in days). }\end{array}$ & Minimize \\
\hline Flexibility & $\begin{array}{l}\text { Related to the acceptability of the supplier regarding changes of amount or } \\
\text { delivery date of purchase orders. Measured on a verbal scale: } 1=\text { not flexible } \\
\text { and } 5=\text { very flexible. }\end{array}$ & Maximize \\
\hline
\end{tabular}

At this point, it is possible to build the decision matrix, with the performance of each alternative evaluated with respect to each criterion (see Table 2).

An important issue to point out here is regarding what comes to the complexity of this decision-making problem. Even though there are only five alternatives, seven criteria are considered to evaluate these alternatives, which can be considered relatively complex for the challenges of preference modeling, particularly with a compensatory rationality. The complexity of an MCDM/A model is in the number of criteria, whereas in a computational analysis it might be considered in the number of alternatives. The main challenge in an MCDM/A model is to build the DM's preference modeling and incorporate the DM's preference in the mathematical decision model [7, 28-30]. On the other hand, one of the curiosities of the FITradeoff is that the number of alternatives is not a relevant issue. At the very beginning of the FITradeoff process, the number of potentially optimal alternatives (POA) is reduced to a number between 1 and 7 in more than $95 \%$ of cases, based on simulations conducted [31].

Therefore, the preference modeling was carefully conducted with the DM with the FITradeoff method. The subsequent steps of the model in Figure 2 are explained in the following subsections.

4.1. Preference Modeling with FITradeoff. The third step of the model proposed in Figure 2 consists of ranking criteria weights, considering the DM's preferences. In this step, the DM holistically evaluates the criteria in order to rank them according to his/her preferences, considering not only the relative importance of each criterion but also the range of values of the consequences (Keeney and Raiffa [7]). The order obtained by the DM was

$$
\begin{aligned}
k_{\text {price }} & >k_{\text {freight }}>k_{\text {accuracy }}>k_{\text {quality }}>k_{\text {flexibility }} \\
& >k_{\text {lead time }}>k_{\text {promptness }} .
\end{aligned}
$$

The next step is to elicit scale constants based on the FITradeoff method. After ranking the criteria weights, the

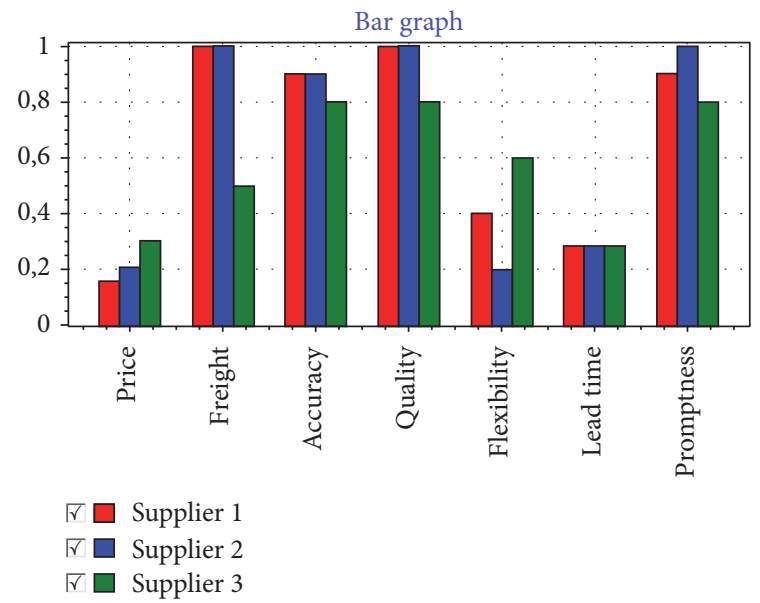

FIGURE 3: Bar graphic of potentially optimal alternatives.

LPP model shown in Section 3 runs in order to look for potentially optimal alternates in the current space of weights [6]. Suppliers 1, 2, and 3 were found as potentially optimal alternatives at this point, and Suppliers 4 and 5 were eliminated. FITradeoff DSS provides the DM with graphical visualization of partial results during the process, which characterizes the flexibility of this method. Figure 3 shows the bar graphic provided by the DSS, which can help the DM to compare the performances of the current potentially optimal alternatives.

Criteria are ordered from left to right, and the performance of the alternatives in each criterion is represented by the bars (one color for each alternative). The height of each bar represents the value of the consequence of an alternative in one criterion, normalized on a $0-1$ ratio scale. By analyzing Figure 3, the DM can holistically compare these three alternatives in order to decide whether or not this partial result is already sufficient for him to make a final decision.

Advantages of using graphics in decision process have been discussed in the literature [32] and particularly as to applying them in multicriteria decision problems [33]. This is an interesting trend that seeks to improve flexibility in 
TABLE 2: Decision matrix of the supplier selection problem.

\begin{tabular}{lccccccc}
\hline Alternatives/criteria & Price & Freight & Accuracy & Promptness & Quality & Lead time & Flexibility \\
\hline Supplier 1 & 17,44 & 1 & 0.9 & 0.9 & 1 & 45 & 2 \\
Supplier 2 & 16,43 & 1 & 0.9 & 1 & 0.8 & 0.8 & 45 \\
Supplier 3 & 14,38 & 0.5 & 0.8 & 0.95 & 0.75 & 45 & 63 \\
Supplier 4 & 20,69 & 0.7 & 1 & 1 & 0,5 & 45 \\
Supplier 5 & 20,69 & 1 & 1 & & & 4 \\
\hline
\end{tabular}

Decision Support Systems (DSS). One of the main issues for graphical visualization in decision processes is the level of confidence of the analysis, for which more studies are required. In this context, cognitive neuroscience and decision neuroscience appear as recent multidisciplinary approaches [34], which can be applied to improve the confidence of visualization tools in DSS and can also be applied to evaluate reduction on the cognitive effort in decision problems.

For this application in a supplier selection problem, the DM has chosen to start answering the elicitation questions because doing holistic evaluation based on the graphic in Figure 3 was still cognitively difficult for him, since all the three alternatives seem to have good outcomes for the problem. This kind of judgment is supported by a set of recommendations that is given to the analyst, which is obtained from the decision neuroscience studies for the FITradeoff method, also using eye tracking tools [34].

Thus, the DM answered the first elicitation question, and the set of potentially optimal alternatives remained the same: Suppliers 1, 2, and 3. After he answered the second question, a unique solution was found: Supplier 2 .

Table 3 has a summary of the application of FITradeoff, where the first column (cycle) indicates the number of the question answered. The second and third columns show the values of consequences $\mathrm{A}$ and $\mathrm{B}$ compared by the DM (for details, see [6]), and the fourth column shows the answer given by the DM. The last column shows the set of potentially optimal alternatives obtained by the LPP model after that question.

In FITradeoff, at each cycle, the DM is required to state his/her preference between two consequences (A and B), but he/she may also be indifferent between them or choose not to answer such question, so that the model computes another question with no loss of information [6]. In the first question, the DM preferred consequence A over consequence $B$, but he was indifferent between the consequences of the second question. A final solution was found immediately after he answered the second question.

The last step of the model, proposed in Figure 1, is to analyze the results obtained. These are discussed in the next subsection.

4.2. Discussion of Results. On analyzing the result obtained by FITradeoff, one should note that the supplier selected (Supplier 2) is not the one that offers the lowest price, which confirms the statement that selecting a supplier based only on cost factors may not represent the best compromise solution for the supply chain as a whole. Supplier 3 is the one with the best price, but compared to Suppliers 1 and 2, it has the

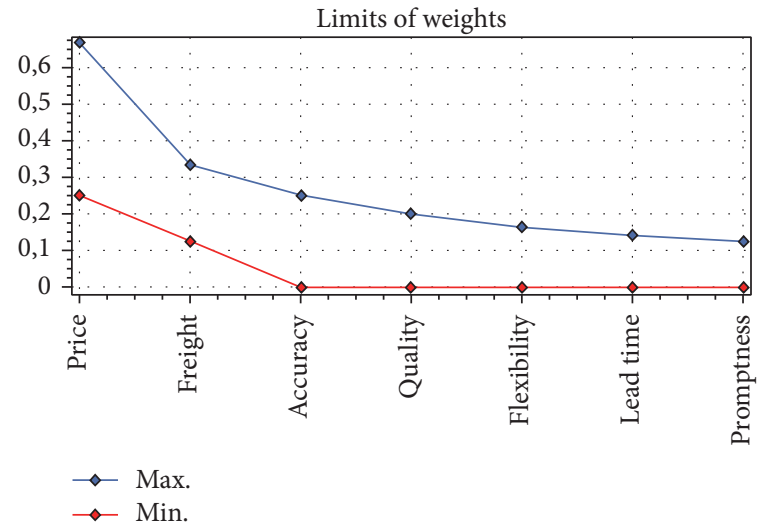

FIgURE 4: Final weight space obtained by FITradeoff.

worst performance on most of the criteria (freight, accuracy, quality, and promptness), as Figure 3 shows. Therefore, these results show how important it is to consider a multiple criteria approach in order to deal with supplier selection problems.

Unlike traditional methods in which exact values for scale constants are obtained (e.g., [7, 35]), FITradeoff works with a set of feasible vectors of weights, or weight space, within which a search for potentially optimal alternatives is made by the LPP model. Therefore, after a final solution was found (Supplier 2), no exact values of weights were calculated, but a final weight space, for which Supplier 2 is the best alternative, was obtained. The final weight space achieved at the end of the application is illustrated in Figure 4, represented by the minimum and maximum values for each scale constant.

For any set of weight vectors inside such a space, the global value of alternative 2 is greater than the global value of any of the other alternatives. Thus, by analyzing Figure 4, one can see that Supplier 2 is the best alternative for a relatively large range of weight values, thus showing that the result obtained is reasonably robust.

With regard to the applicability of the method from the DM's point of view, it could be seen that the number of questions needed to find a final solution was only 2 , which shows that FITradeoff did not require the DM to make much effort to solve this problem. The quantity of questions required by the FITradeoff method to find a unique solution to MCDM problems in general is not a fixed number; it may vary according to the data of the problem; in particular, two key aspects have influence on this issue: the topology of the alternatives and the distribution of criteria weights. There are some cases in which right after the ranking of criteria weights 
TABLE 3: Summary of FITradeoff application.

\begin{tabular}{lcccc}
\hline Cycle & Consequence A & Consequence B: best of & Answer & Potentially optimal alternatives \\
\hline 0 & & & Ordering... & Supplier 1, Supplier 2, Supplier 3 \\
1 & 17.53 of price & Promptness & A & Supplier 1, Supplier 2, Supplier 3 \\
2 & 17.53 of price & Freight & I & Supplier 2 \\
\hline
\end{tabular}

a solution can be found; in other cases, even more than 10 questions might be necessary [6]. For this specific supplier selection problem addressed here, only two questions were necessary in order to find a final solution for the problem.

As explained in Section 3, all questions put for the DM in the FITradeoff Decision Support System ask him to compare the following: consequence $\mathrm{A}$, with an intermediate value for one criterion and the worst value for the others, and consequence $\mathrm{B}$, with the best value for one criterion and the worst value for the others. The DM has four possible answers for such questions: preference for consequence A; preference for consequence $\mathrm{B}$; indifference between these two consequences; or choosing not to answer the question (because he does not want to or is not willing to). In this supplier selection problem, Table 3 shows that the second question put for the DM by the FITradeoff DSS was the following: consequence A, with $\mathrm{R} \$ 17.35 / \mathrm{kg}$ value for the price and worst value for the other criteria, and consequence B, with the best outcome for freight (which is 1, according to Table 2) and the worst outcome for the others. The DM had the option to answer in any of the four ways explained above, but, according to his preferences, he felt indifferent between these two consequences. Therefore, he did not have to exactly specify an indifference value because the method requires that (as happens in the traditional tradeoff procedure [7]), but instead he chose to give such information. If the traditional tradeoff procedure was applied to solve this problem, at least 6 (number of criteria - 1) indifference statements would be mandatory in order to find a solution. In FITradeoff, the DM does not necessarily give indifference statements, but he is allowed to if so he desires because of the flexibility of this method.

Thus, a reduction in the number of questions was reached by applying FITradeoff, and the cognitive effort may also be reduced depending on the answers given by the DM. Time is precious and in short supply for managers of multinational companies, so they are always looking to reduce the effort and time spent with processes like decision-making, which puts forward FITradeoff as a good alternative of MCDM method for aiding this problem.

The DSS used in this application is available for download on request at http://fitradeoff.org/.

\section{Conclusions}

Given the increasing competitiveness of organizations, it is important to give special attention to key decisions that can improve a company's results, such as how best to select suppliers. In this context, this paper presented a structured multiple criteria approach for tackling the problem of selecting a supplier of packaging material to a food company.
Seven criteria were selected to represent the objectives related to this particular problem, and five vendors were evaluated with respect to these criteria. The preference modeling was conducted considering a purchasing manager's preferences within a compensatory approach, aided by the Flexible and Interactive Tradeoff (FITradeoff) method.

The elicitation process in FITradeoff was conducted with the DM by means of a Decision Support System, in which the DM interactively answers questions, and then potentially optimal alternatives are sought by solving linear programming problems. FITradeoff DSS also provides graphical visualization for the DM at each step in a flexible way, so that the DM can holistically analyze the performance of the potentially optimal alternatives. This method has been supported by studies based on neuroscience [34].

After two elicitation questions answered by the DM, the DSS found a final solution for the problem. An interesting thing to point out is the fact that the selected alternative was not the one presenting the best price offer, which most of the time is the only attribute considered by companies in order to make this kind of decision. Thus, evidence that approaches considering only cost factors may not result in the best compromise solution for a company is provided.

An advantage of applying FITradeoff to solve this problem can be observed by comparing it to the traditional tradeoff elicitation procedure. If the traditional tradeoff was to be applied, a minimum of six indifference statements $(n-1)$ from the DM would be required to find a final solution. Indifferent statements are cognitively difficult to provide, and FITradeoff does not necessarily require this kind of information. Partial information can be provided with strict preference statements. With FITradeoff, only two questions were necessary to find a final compromise solution, which resulted in the DM saving time and effort.

\section{Conflicts of Interest}

The authors declare that there are no conflicts of interest regarding the publication of this article.

\section{Acknowledgments}

The authors would like to acknowledge CNPq for the partial financial support for this research.

\section{References}

[1] P. Parthiban, H. Abdul Zubar, and P. Katakar, "Vendor selection problem: A multi-criteria approach based on strategic decisions," International Journal of Production Research, vol. 51, no. 5, pp. 1535-1548, 2013. 
[2] S. Soner Kara, "Supplier selection with an integrated methodology in unknown environment," Expert Systems with Applications, vol. 38, no. 3, pp. 2133-2139, 2011.

[3] W. Xia and Z. Wu, "Supplier selection with multiple criteria in volume discount environments," Omega, vol. 35, no. 5, pp. 494504, 2007.

[4] W. Ho, X. Xu, and P. K. Dey, "Multi-criteria decision making approaches for supplier evaluation and selection: a literature review," European Journal of Operational Research, vol. 202, no. 1, pp. 16-24, 2010.

[5] J. Chai, J. N. K. Liu, and E. W. T. Ngai, "Application of decisionmaking techniques in supplier selection: a systematic review of literature," Expert Systems with Applications, vol. 40, no. 10, pp. 3872-3885, 2013.

[6] A. T. de Almeida, J. A. de Almeida, A. P. C. S. Costa, and A. T. de Almeida-Filho, "A new method for elicitation of criteria weights in additive models: flexible and interactive tradeoff," European Journal of Operational Research, vol. 250, no. 1, pp. 179-191, 2016.

[7] R. L. Keeney and H. Raiffa, Decision Analysis with Multiple Conflicting Objectives, Wiley \& Sons, New York, NY, USA, 1976.

[8] A. A. Salo and R. P. Hämäläinen, "Preference assessment by imprecise ratio statements," Operations Research, vol. 40, no. 6, pp. 1053-1061, 1992.

[9] M. Weber, "Decision making with incomplete information," European Journal of Operational Research, vol. 28, no. 1, pp. 44$57,1987$.

[10] A. Jiménez, A. Mateos, and P. Sabio, "Dominance intensity measure within fuzzy weight oriented MAUT: An application," OMEGA - The International Journal of Management Science, vol. 41, no. 2, pp. 397-405, 2013.

[11] E. A. Aguayo, A. Mateos, and A. Jiménez, "A new dominance intensity method to deal with ordinal information about a DM's preferences within MAVT," Knowledge-Based Systems, vol. 69, no. 1, pp. 159-169, 2014.

[12] A. Mateos, A. Jiménez-Martín, E. A. Aguayo, and P. Sabio, "Dominance intensity measuring methods in MCDM with ordinal relations regarding weights," Knowledge-Based Systems, vol. 70, pp. 26-32, 2014.

[13] A. Slack, S. Chambers, and R. Johnston, Operations and process management: principles and practice for strategic impact, Pearson Education, 2009.

[14] C. A. Weber and J. R. Current, "A multiobjective approach to vendor selection," European Journal of Operational Research, vol. 68 , no. 2, pp. 173-184, 1993.

[15] A. T. De Almeida, C. A. V. Cavalcante, M. H. Alencar, R. J. P. Ferreira, A. T. De Almeida-filho, and T. V. Garcez, "Multicriteria and Multi-objective Models for Risk, Reliability and Maintenance Decision Analysis," in International Series in Operations Research \& Management Science, vol. 231, Springer, New York, NY, USA, 2015.

[16] F. Dweiri, S. Kumar, S. A. Khan, and V. Jain, "Designing an integrated AHP based decision support system for supplier selection in automotive industry," Expert Systems with Applications, vol. 62, pp. 273-283, 2016.

[17] L.-h. Li, J.-c. Hang, Y. Gao, and C.-y. Mu, "Using an integrated group decision method based on SVM, TFN-RS-AHP, and TOPSIS-CD for cloud service supplier selection," Mathematical Problems in Engineering, vol. 2017, Article ID 3143502, 14 pages, 2017.
[18] S. Çakır, "Selecting the best supplier at a steel-producing company under fuzzy environment," International Journal of Advanced Manufacturing Technology, vol. 88, no. 5-8, pp. 13451361, 2017.

[19] M. Dursun and E. E. Karsak, "A QFD-based fuzzy MCDM approach for supplier selection," Applied Mathematical Modelling, vol. 37, no. 8, pp. 5864-5875, 2013.

[20] Z. Xiao, W. Chen, and L. Li, "An integrated FCM and fuzzy soft set for supplier selection problem based on risk evaluation," Applied Mathematical Modelling: Simulation and Computation for Engineering and Environmental Systems, vol. 36, no. 4, pp. 1444-1454, 2012.

[21] S. Hamdan and A. Cheaitou, "Supplier selection and order allocation with green criteria: an MCDM and multi-objective optimization approach," Computers \& Operations Research, vol. 81, pp. 282-304, 2017.

[22] D. Kannan, K. Govindan, and S. Rajendran, "Fuzzy axiomatic design approach based green supplier selection: a case study from Singapore," Journal of Cleaner Production, vol. 96, pp. 194208, 2015.

[23] C.-W. Tsui and U.-P. Wen, "A hybrid multiple criteria group decision-making approach for green supplier selection in the TFT-LCD industry," Mathematical Problems in Engineering, vol. 2014, Article ID 709872, 13 pages, 2014.

[24] T. E. E. Gonçalo and L. H. Alencar, "A supplier selection model based on classifying its strategic impact for a company's business results," Pesquisa Operacional, vol. 34, no. 2, pp. 347-369, 2014.

[25] A. Awasthi, S. S. Chauhan, and S. K. Goyal, "A fuzzy multicriteria approach for evaluating environmental performance of suppliers," International Journal of Production Economics, vol. 126, no. 2, pp. 370-378, 2010.

[26] A. P. Henriques De Gusmão and C. Pereira Medeiros, "A Model for Selecting a Strategic Information System Using the FITradeoff," Mathematical Problems in Engineering, vol. 2016, Article ID 7850960, 7 pages, 2016.

[27] M. Weber and K. Borcherding, "Behavioral influences on weight judgments in multiattribute decision making," European Journal of Operational Research, vol. 67, no. 1, pp. 1-12, 1993.

[28] V. Belton and T. Stewart, Multiple criteria decision analysis: an integrated approach, Springer Science Business Media, 2002.

[29] S. Greco, J. Figueira, and M. Ehrgott, "Multiple criteria decision analysis," in Springer's International series, 2005.

[30] J. Pomerol and S. Romero, Multicriterion Decision in Management: Principles and Practice, Springer Science \& Business Media, 2012.

[31] A. T. de Almeida-Filho, A. T. de Almeida, and A. P. Costa, "A flexible elicitation procedure for additive model scale constants," Annals of Operations Research, pp. 1-19, 2017.

[32] R. K. Anderson and M. Dror, "An interactive graphic presentation for multiobjective linear programming," Applied Mathematics and Computation, vol. 123, no. 2, pp. 229-248, 2001.

[33] E. Kasanen, R. Östermark, and M. Zeleny, "Gestalt system of holistic graphics: New management support view of MCDM," Computers and Operations Research, vol. 18, no. 2, pp. 233-239, 1991.

[34] A. T. de Almeida and L. R. Roselli, "Visualization for Decision Support in FITradeoff Method: Exploring Its Evaluation with Cognitive Neuroscience," in Decision Support Systems VII. Data, Information and Knowledge Visualization in Decision Support 
Systems, vol. 282 of Lecture Notes in Business Information Processing, pp. 61-73, Springer International Publishing, 2017.

[35] W. Edwards and F. H. Barron, "SMARTS and SMARTER: improved simple methods for multiattribute utility measurement," Organizational Behavior and Human Decision Processes, vol. 60, no. 3, pp. 306-325, 1994. 


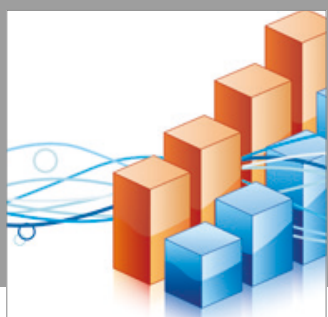

Advances in

Operations Research

vatersals

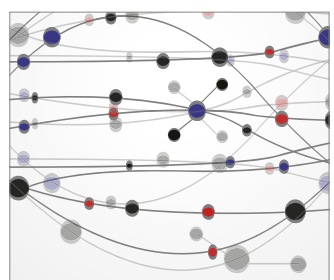

\section{The Scientific} World Journal
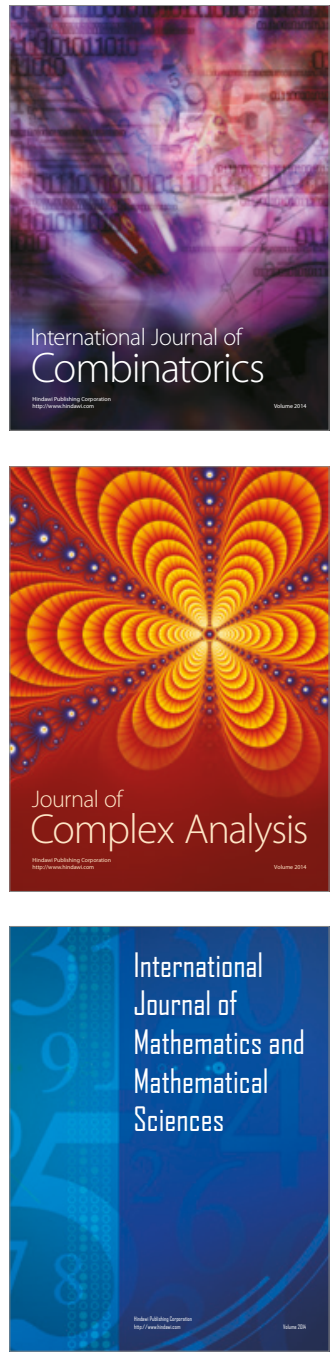
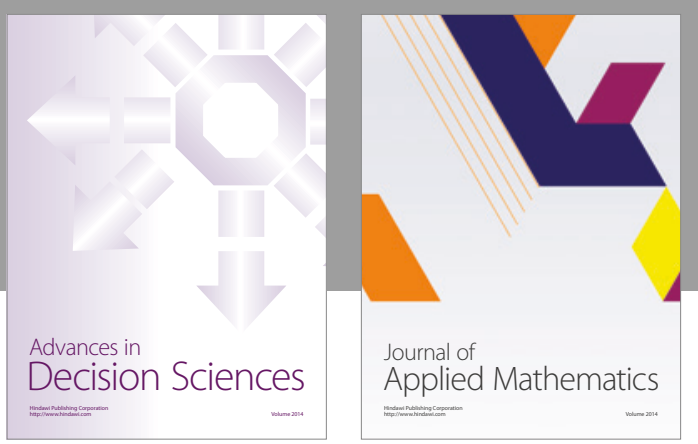

Algebra

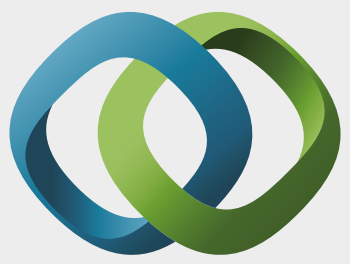

\section{Hindawi}

Submit your manuscripts at

https://www.hindawi.com
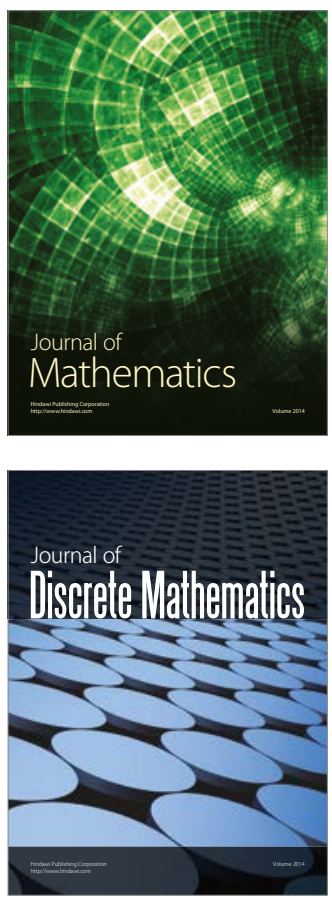

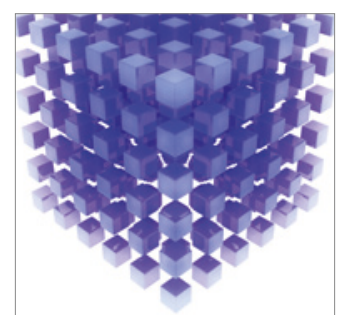

Mathematical Problems in Engineering
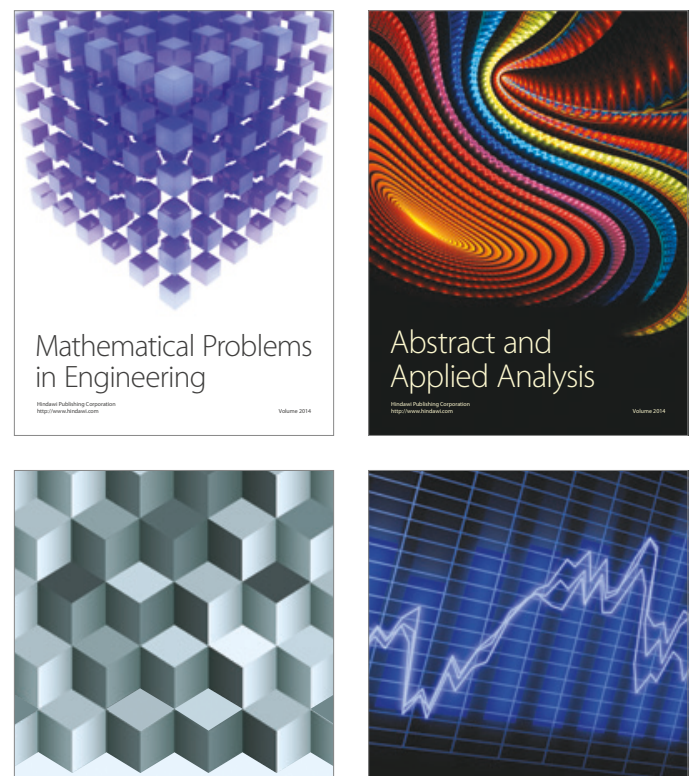

Journal of

Function Spaces

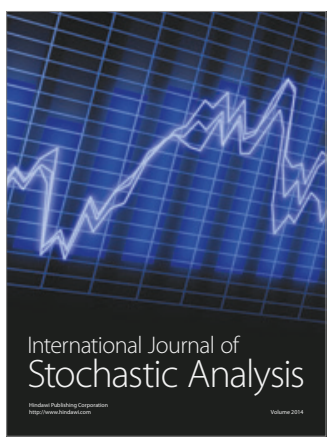

Probability and Statistics
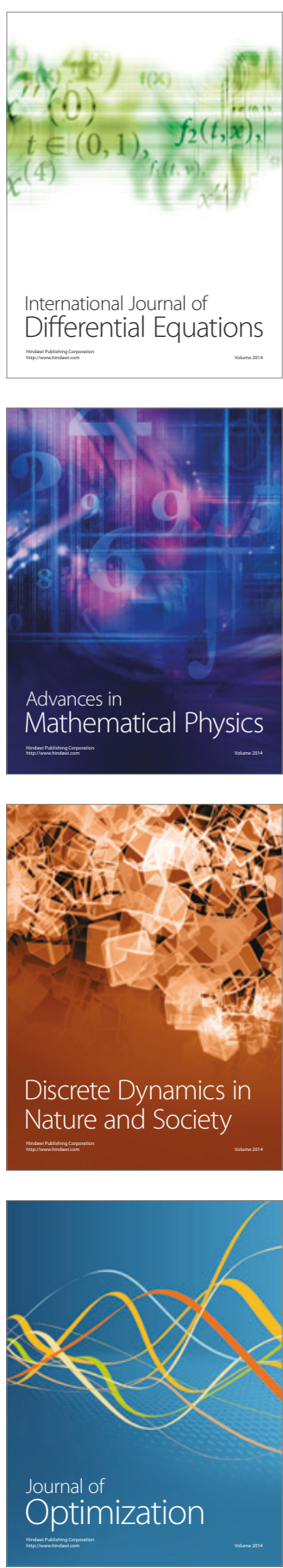